\title{
109. On the Chemical Reaction Between Metallic Magnesium and Aqueous Chloride Solutions.
}

By Ichirô IITAKA.

Research Laboratory, Mitsubishi Company Ltd., Tokyo.

(Rec. Oct. 15, 1930. Comm. by K. Tawara, M.I.A., Nov. 12, 1930.)

Metallic magnesium reacts with soldium chloride solutions so rapidly as zinc dissolving in acids. After a while, a white precipitate begins to deposit which continues to accumulate more and more. After some days, small specimens disintegrate completely into powders. This is a phenomenon of a very peculiar kind, because $\mathrm{Mg}$ is too negative to replace $\mathrm{Na}^{+}$ion, and magnesium scarcely decomposes water. The reaction is very intense and the velocity can be measured within some minutes or hours. It can not be considered as ordinary corrosion which occurs exceedingly slowly. The present writer investigated this phenomenon both in qualitative and quantitative ways and proposed a new theory.

The reaction was found to take place equally vigorously in various chlorides solutions, such as $\mathrm{KCl}, \mathrm{BaCl}_{2}, \mathrm{SrCl}_{2}, \mathrm{CaCl}_{2}, \mathrm{MgCl}_{2}, \mathrm{AlCl}_{3}$, $\mathrm{MnCl}_{2}, \mathrm{ZnCl}_{2}$, showing that cathions do not participate in the reaction mechanism. Magnesium reacts scarcely with nitrate, sulphate, phosphate and acetate solutions, which shows that anions except $\mathrm{Cl}^{-}$do also not contribute to the mechanism. It reacts as well with the solutions made from carefully redistilled water and deprived of dissolved gases by boiling showing that gases such as $\mathrm{O}_{2}, \mathrm{~N}_{2}, \mathrm{CO}_{2}$, are not the cause of the reaction. The reactions of the metals of alkali and alkaline earth groups against water, dilute acids and alkali hydroxide solutions were next investigated. The results are given in Fig. 1 for Li metal. The ordinates indicate the reaction velocities (V), the velocity of the reaction against water being put equal to 100 , while the abscissa the logarithms of concentrations ( $\mathrm{N}$ or $\left[\mathrm{H}^{+}\right]$). Each curve for respective acid is separated into four parts or sections. In Sections III and IV is revealed the effect of large viscosity of relatively concentrated solutions. The chemical change occurring in Section I involves certainly the ordinary ionic reaction expressed as follows:

$$
2 \mathrm{H}^{+}+2 \mathrm{Li} \rightarrow \mathrm{H}_{2} \text { (gas) }+2 \mathrm{Li}^{+}
$$

This reaction retards with diminution of $\left[\mathrm{H}^{+}\right]$becoming invisible at $10^{-3}$. And it naturally follows that the residual reaction after $\left[\mathrm{H}^{+}\right]$ has infinitely approached to zero, viz. the reaction of Section II, still 
so intense with a velocity equal to 100 , is independent of $\mathrm{H}^{+}$. The hydrogen gas evolved must, therefore, come out directly from water molecule. And we are led to consider a molecular reaction expressed as follows :

$$
2 \mathrm{H}_{2} \mathrm{O}+2 \mathrm{Li} \rightarrow \mathrm{H}_{2} \text { (gas) }+2 \mathrm{Li}^{+}+2 \mathrm{OH}^{-}
$$

The reactions of magnesium are summarized in Fig. 2. The case when the solution contains no $\mathrm{Cl}^{-}$is shown in curve 1 . Vigorous reaction of equation (I) occurs at $\left[\mathrm{H}^{+}\right]>10^{-4}$, but in solutions of $\left[\mathrm{H}^{+}\right]<10^{-4}$, the reaction stops immediately owing to the formation of protecting film at the surfarce. The results with $\mathrm{NaCl}$ solutions of $10^{-2}$ normal are given by the curves 2 and 3, in the former the solution was kept still, while in the latter it was stirred. Each curve is separated into three sections. In Section I, which covers the region of $\left[\mathrm{H}^{+}\right]>10^{-4}$, the reaction amount decreases with $\left[\mathrm{H}^{+}\right]$; the chemical change of this section involves naturally the ionic reaction of the following equation

$$
2 \mathrm{H}^{+}+\mathrm{Mg} \rightarrow \mathrm{H}_{2} \text { (gas) }+\mathrm{Mg}^{++}
$$

Section III shows the influence of viscosity. When the reaction amounts are plotted against $\left[\mathrm{H}^{+}\right]$instead of $\log \left[\mathrm{H}^{+}\right]$, and the limiting case when $\left[\mathrm{H}^{+}\right]$has infinitely approached to zero is considered, it is found that there still remains a large residual reaction, amounting to 80 on still standing and 25 on stirring. Moreover, the reaction amount keeps constant throughout the wide range of $\log \left[\mathrm{H}^{+}\right]$from -4 to -11 . The reaction of Section I was found to accelerate several times when stirred, that of Section II, on the contrary, retards to the same extent as illustrated in Fig. 2; both reactions behave oppositely on stirring. From these three facts we came to the conclusion that there exists in Section II another chemical reaction differing from (I) and independent of $\mathrm{H}^{+}$ion. This is a kind of molecular reactions and may be expressed as follows:

$$
2 \mathrm{H}_{2} \mathrm{O}+\mathrm{Mg} \rightarrow \mathrm{H}_{2} \text { (gas) }+\mathrm{Mg}^{++}+2 \mathrm{OH}^{-}
$$

That the reaction accelerates on leaving still indicates that some reaction product catalyses the reaction itself. The minimum points of the curves are explained by decomposition of this catalyser.

A dual theory finally put forward by the author is expressed as follows :

Metallic magnesium reacts with dilute acids of $\left[\mathrm{H}^{+}\right]>10^{-4}$ and replaces $\mathrm{H}^{+}$expelling hydrogen gas \{equation (I)\}. This reaction retards with $\left[\mathrm{H}^{+}\right]$and reaches a limiting value at $\left[\mathrm{H}^{+}\right]=10^{-4}$. In solutions $\left[\mathrm{H}^{+}\right]<10^{-4}$ the reaction proceeds somewhat at the beginning 
No. 9.] On the Chemical Reaction Between Metallic Magnesium and Aqueous. 365

but soon comes to an end as the surface is covered and protected by oxide film. Although $\mathrm{Cl}^{-}$ion above $10^{-3}$ normal will break down this film the reaction can not proceed fast with such minute concentration of $\mathrm{H}^{+}$. Therefore, the author introduced another reaction of equation (2) and gave a satisfactory explanation for the large reaction velocity and its independence of $\left[\mathrm{H}^{+}\right]$. To explain the stirring effect an intermediate compound was assumed, which, when accumulated at the surface on still standing catalyses the reaction (2), but the reaction retards when it is scattered away on stirring. The minimum points of the curves were explained by assuming that this compound becomes unstable above $\left[\mathrm{H}^{+}\right]=10^{-4}$.

The further details of this paper will be published on the Journal of the Iron and Steel Institute of Japan, "Tetsu to Hagane."

Fig. 1 .

The reaction of $\mathrm{Li}$ metal against water, dilute acids and alkali hydroxide solutions.

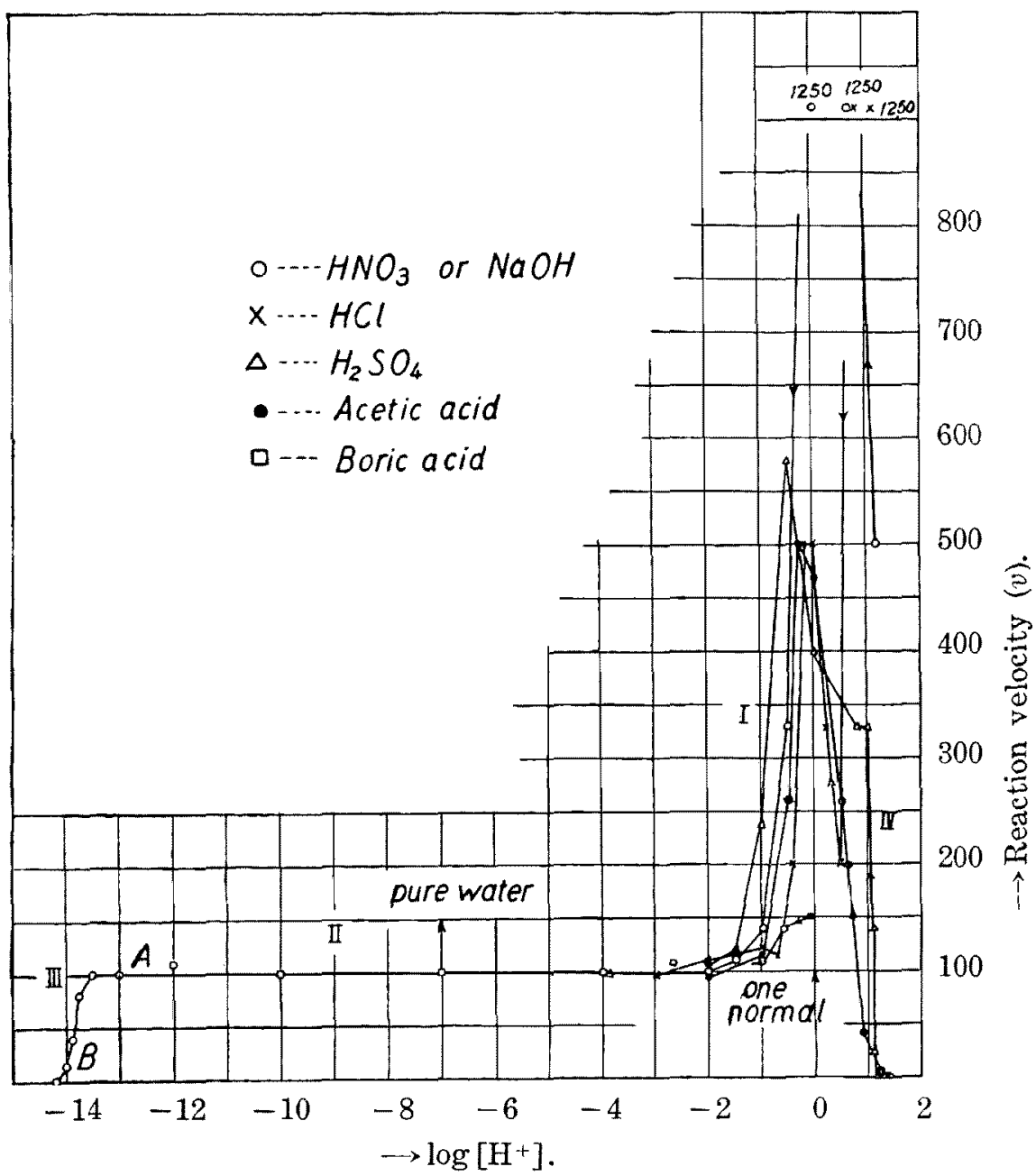




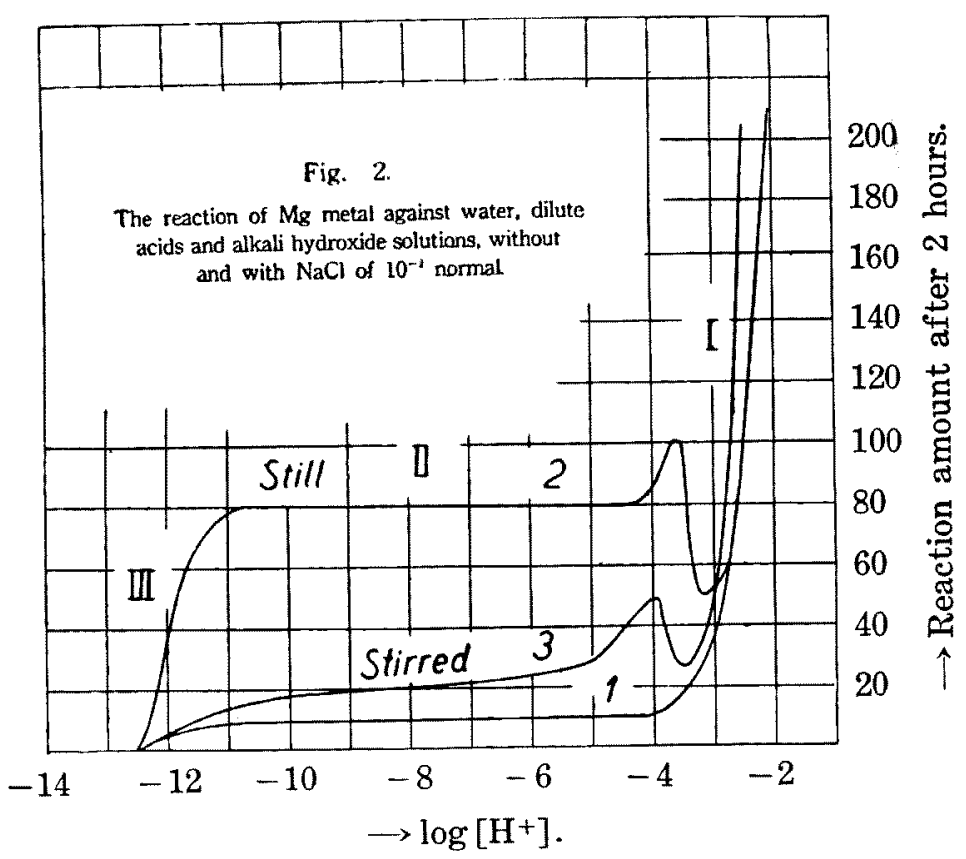

